Kansas State University Libraries

New Prairie Press

\title{
THE POWER OF STRUCTURED DESIGNS AND MIXED MODELS IN A REAL WORLD EXPERIMENT
}

\author{
J. C. Galland \\ G. A. Milliken \\ D. R. Hyatt \\ M. Hornback \\ K. Cudjoe
}

See next page for additional authors

Follow this and additional works at: https://newprairiepress.org/agstatconference

Part of the Agriculture Commons, and the Applied Statistics Commons

\section{(c) (1) $\Theta(9$}

This work is licensed under a Creative Commons Attribution-Noncommercial-No Derivative Works 4.0 License.

\section{Recommended Citation}

Galland, J. C.; Milliken, G. A.; Hyatt, D. R.; Hornback, M.; and Cudjoe, K. (1999). "THE POWER OF STRUCTURED DESIGNS AND MIXED MODELS IN A REAL WORLD EXPERIMENT," Conference on Applied Statistics in Agriculture. https://doi.org/10.4148/2475-7772.1271

This is brought to you for free and open access by the Conferences at New Prairie Press. It has been accepted for inclusion in Conference on Applied Statistics in Agriculture by an authorized administrator of New Prairie Press. For more information, please contact cads@k-state.edu. 


\section{Author Information}

J. C. Galland, G. A. Milliken, D. R. Hyatt, M. Hornback, and K. Cudjoe 


\title{
The Power of Structured Designs and Mixed Models in a Real World Experiment
}

\author{
J. C. Galland, Kansas State University \\ G.A. Milliken, Kansas State University \\ D.R. Hyatt, Kansas State University \\ M. Hornback, Kansas State University \\ K. Cudjoe, Norwegian College of Veterinary Medicine (Norway)
}

\section{INTRODUCTION}

Justifications usually given for adopting an automated system pertain to a reduction in labor and an improvement in quality control. A manufacturer of a prototype instrument that automated some of the steps for culturing bacteria wanted to compare the automated system to the manual system. The manufacturer wanted to compare the two systems in

1) Total time needed to isolate the target bacteria,

2) Ability to isolate the target bacteria,

3) Amount of interference from background (non-target) bacterial growth, and

1) Extent of cross (sample to sample) contamination.

This paper presents the experimental design used to make these comparisons and how the design helped discover some surprising results about laboratory quality control. The experiment presented illustrates the importance of a good experimental design, the power of current statistical tools, and that a thorough and appropriate analysis of a data set requires side-by-side good detective work by both statistician and client.

\section{METHODS}

\section{The Instrument}

The instrument was designed to help isolate a target species of bacteria from a sample such as water or feces. Both automated and manual systems use immunomagnetic beads that are added to the sample and bind the target organisms in the sample to the beads. To better assure that any target organisms come in contact with the beads; the sample and bead mixture was shaken or mixed. To wash away any sample debris and non-targeted bacteria from the beads, the beads are washed several times. Finally, the bead slurry was spread in a specific pattern (streaked) with an inoculating loop on a growth media in a petri dish and incubated. This process is called plating. After incubation, a microbiologist counts the number of bacterial colonies that have grown. Colonies of the target organism are distinguished from other colonies based on their unique color and morphology. Additional tests may be done to confirm that the colony is a pure colony of the target organism. The prototype instrument automates the mixing and washing steps. The instrument can process up to 15 samples simultaneously. Samples are placed into 1 of 3 racks that fit into the 
instrument; each rack can hold up to 5 samples. For the manual system, any number of racks holding up to 10 samples each can be used on a laboratory bench top.

\section{Protocol}

The specifications presented to the microbiology laboratory from the manufacturer for comparing the two systems (A or automated vs. M or manual) were general: They requested that a total of 150 samples be tested by both systems, and for control purposes, that a third of the samples be artificially contaminated (spiked) with the target species. They requested that contaminated samples be alternated with negative (blank) samples such that one could determine cross contamination from either aerosols or test performers. They further requested that two types of media (CA vs. CT) be used to grow bacteria "captured" by the beads. One growth medium (CT) contained antibiotics that reduce non-target organisms from growing without reducing growth of target organisms. The other media (CA) did not contain antibiotics.

\section{Statistical Design}

The microbiologist consulted a statistician to assist in developing a design that would fulfill the needs of the instrument manufacturer and accommodate the "rush" nature of the experiment and other limitations placed on the laboratory. The instrument was designed with an unequal number of sample holders (5/rack) so all treatments and blanks could not be accommodated simultaneously or divided equally to fill all positions in the rack.

The treatment structure (Milliken and Johnson, 1992) consisted of five factors. The first factor was the material assayed (water and feces). The second factor was Mode of the material; whether the sample of material was autoclaved killing any bacteria in the material (sterile) or not autoclaved (raw). The third factor was type of system (automated and manual). The fourth factor was whether the sample was artificially contaminated (spiked) with a high, medium, or low concentration (denoted by S1, S2, or S3 obtained through a dilution process) or not spiked. The fifth factor was the two types of media (CA or CT) that were used to plate the samples. These treatment combinations were evaluated in two experiments. The first experiment used S1 (the highest level of spiking) in three Mode-material combinations (sterile water, sterile feces and raw feces) and unspiked (S0) sterile water for both types of systems. The second experiment used S2 and S3 in the three Mode-material combinations and S0 in both sterile and raw feces for both types of systems.

There were four factors in the design structure (Milliken and Johnson, 1992) for both experiments (Table 1). The first factor in the design structure was source of the material. The feces came from 15 different fecal pats (patty) and the sterile water came from 14 different batches. The second factor of the design structure was cycles and the third factor was runs within cycles made by either the automated or manual systems. A cycle consisted of one run or two consecutive runs of either system preformed by the same technician. The fourth factor of the design structure was the technician $(\mathrm{MH}$ or $\mathrm{DH})$ that operated a system during a given cycle. This structured design permitted main effect comparisons to be made between systems, levels of spiking, materials, growth 
medium, as well as estimates of variance components associated with technicians, cycles, runs (cycles), patties and interactions between the design structure and treatment structure factors. In previous analyses, rack $(1,2$, or 3$)$ and position within rack ( 1 through 5 for the automated system and 1 through 10 for the manual system) were found to be insignificant (providing zero estimates of the variance components) and were excluded from further analyses.

\section{Randomization and Allocation of Experimental Units}

The factors in the experiments were divided into a rectangular array of rows and columns. The rows and columns form a strip-plot design structure.

The rows of Table 1 were the fecal pats or batches of water. A pat of feces was mixed and evenly split into 2 containers. One container was autoclaved (sterile and the other half was not (raw)). From each container, one gram of feces was removed and put into a tube containing sterile liquid growth media. This was repeated until a total of 4 tubes from each container were made. Tubes were refrigerated until needed. On the morning of the experiment, all tubes were inoculated with either sterile water (S0) or dilutions of the target organism (S1, S2, and S3).

Figures 1 and 2 illustrate how the materials (patty and water batches) were divided into the tubes. A patty was split into two halves where one half was sterilized and the other kept in the raw Mode. Then the material was put into tubes, where some tubes were examined in experiment 1 (E1) and some in experiment 2 (E2). Figure 2 illustrates that the content of a tube was spread onto two different media.

The columns of Table 1 (experiments, cycles, and runs) were experiments, cycles within experiments and runs within cycles within experiments. Within an experiment, we assigned a technician randomly to a system to begin the experiment; thereafter technicians were alternated between systems after every cycle. A single water batch was used during a run within a cycle; thus water batches were assigned randomly to runs within cycles. For experiment 1, we assigned treatments to positions within a rack (Tables 2 and 3) such that spiked samples were alternated with sterile water for the manual system and spiked samples were always adjacent (in both directions) to sterile water for the automated system. For experiment 2, treatments were assigned randomly within a rack such that, where possible because of rack size, samples of the same type (raw, sterile, water or S0) were in the same rack and dilutions $\mathrm{S} 2$ and $\mathrm{S} 3$ were represented at least twice in a rack. The notation S0, S1, S2, and S3 used in Table 1 indicate which treatment combinations were evaluated during which run within a cycle. For sterile water, the number in front of S0, S1, S2, or $\mathrm{S} 3$ indicate the number of times that spiked or not spiked sterile water occurred during a run.

\section{Model construction}

Using the description of the experimental units that form the rows and the experimental units that form the columns, models were constructed for the rows, for the columns and for the intersection of the rows and columns and then the three models were combined to form a single Model. 


\section{Row Analysis}

Pats of manure or batches of water were the experimental units for material (manure or water). For notational convenience, the pats of manure and batches of water were called "pats" and the levels of material were conceptually randomized to a pat (pat of manure or batch of water). The pat part of the analysis was a completely randomized design that had the sources:

Material

Pat (Material)

where PAT (MATERIAL) represented the pat to pat variability denoted as ERROR(pat). Error (pat) would be the error term used to compare levels of material in a balanced design. Since the design used was not balanced, then a combination of error terms including Error (pat) was used to compare the levels of material.

For each pat, a pat was divided into two $1 / 2$ pats and the levels of MODE were randomly assigned to the two one-half pats. Thus, one-half pat was the experimental unit for MODE (raw or sterile). One complication was that there is just one level of MODE for water, i.e. sterile. Conceptually, a batch of water was split into two batches, one batch autoclaved the other batch discarded. Thus, there was just one-half batch of water used from a batch of water. Raw or nonsterile water had no meaning in this experiment. To account for this imbalance, the treatment effects were expressed as MODE (MAT). Thus, the one-half pat part of the analysis consisted of the sources MODE (MAT) and PAT*MODE (MAT) where PAT*MODE(MAT) represents the variability between one-half pats within a pat, denoted by $\operatorname{ERROR}(1 / 2$ pat $) . \operatorname{ERROR}(1 / 2$ pat $)$ would be the appropriate error term for testing MODE(MAT) in a balance design. Since the design used was not balanced, then a combination of error terms including Error( $1 / 2$ pat $)$ was used to compare the levels of MODE(MAT).

The content of one test tube (1/8 of a pat) was the experimental unit for level of dilution(DIL). The material from a one-half pat was put into four large test tubes each representing $1 / 8$ of a pat. The levels of DIL were assigned randomly to these four tubes within each one-half pat. The 1/8 pat part of the analysis had the terms DIL, DIL*MAT, DIL*MODE(MAT) and PAT*DIL*MODE(MAT) where PAT*DIL*MODE(MAT) represents the variability among large test tubes or $1 / 8$ pat sections within a one-half pat and was denoted by ERROR(1/8 Pat). ERROR(1/8 Pat) would be the appropriate error term for constructing F-tests for DIL, DIL*MAT and DIL*MODE(MAT) in a balanced design. Since the design used was not balanced, then a combination of error terms including Error(1/8 pat) was used to compare the levels of DIL, DIL*MAT and DIL*MODE(MAT).

\section{Column Analysis}

The column design consisted of two experiments (EXP) where the cycles within the experiments were the experimental units. The treatment structure was a two-way with System $(A, M)$ crossed with Technician $(D, M)$. The levels of system were considered fixed effects and the levels of Technician were considered random effects. The overall design for the column analysis was a two-way treatment structure ( 4 treatment combinations) in a randomized complete block 
design structure with one block of size six and the other block of size four. In block 1 (experiment 1) the treatment combinations (M, Automated and D, Manual) were replicated twice. The sources in the analysis were EXP, SYSTEM, TECH, SYS*TECH, SYS*TECH*CYCLE(EXP) where SYS*TECH*CYCLE(EXP) measured the variability among cycles within an experiment and was denoted by ERROR(CYCLE). Since some SYS*TECH combinations were observed in more than one cycle, then ERROR(CYCLE) was computed by SYS*TECH*CYCLE(EXP). Since TECH is a random effect, TECH*SYS would be the appropriate divisor for testing about SYS differences if the data set were balanced. Since the design used was not balanced, then a combination of error terms including TECH*SYS was used to compare the levels of SYS.

\section{Intersection of Rows and Columns analysis}

Since the rows and columns form a strip-plot type design structure, the treatment effects associated with the analysis of the intersection of the rows and columns were the interactions between each part of the treatment structure for the rows with each part of the treatment structure for the rows. The treatment structure terms for the rows were MAT, MODE(MAT), DIL, DIL*MAT, DIL*MODE(MAT). The treatment structure terms for the columns were EXP, SYS, SYS*EXP, TECH, EXP*TECH, EXP*SYS, EXP*SYS*TECH. Thus the treatment structure for the intersection of the rows and columns were the interactions formed by interacting each of the treatment structure terms for columns with each of the treatment structure terms for rows. The row by column part of the Model consisted of a total of 35 terms.

Error terms were obtained by interacting each error term for the rows with each error term for the columns. The error terms for the row analysis were PAT*MODE(MAT) and PAT*DIL*MODE (MAT). The error term for the column analysis was SYS*TECH*CYCLE(EXP). The resulting error terms were represented by PAT*MODE*SYS*TECH*CYCLE(EXP MAT) and PAR*MODE*DIL*SYS*TECH*CYCLE(EXP MAT).

All above terms were included in a model to adequately describe the data set.

\section{Response Variable}

The response variable was the natural log of the targeted bacteria count (colony forming units of E. coli $\mathrm{O} 157: \mathrm{H7})$.

\section{Statistical Model}

Proc Mixed of the SAS ${ }^{\circledR}$ system (SAS Institute, Inc. 1989) was used to fit a model to describe the data, provide estimates of the parameters, and test hypotheses. An iterative process of data exploration by statistician and biologist was used to arrive at an acceptable model that described the data well. Seventeen fixed and 8 random effects were included in the model (Table 4). Having so many effects in the model and having enough degrees of freedom for each effect was possible because the design was structured. The structured design further enabled the client to compare the two systems while controlling "extraneous" variance components. 


\section{RESULTS}

Only one interaction DIL*MOD*MED(MAT*EXP) was found to be significant in estimating the observed log target bacteria counts (Table 5). Least squares means were constructed to make over 60 comparisons. The SAS program required over 6 minutes to complete on a 300 $\mathrm{MHz}$ computer. The significant contrasts are listed in Table 6 and the results of the comparisons of interest are given below.

\section{System Effects (Automated vs. Manual)}

No difference in $E$. coli recovery was detected between the two systems $(\mathrm{P}=0.22)$.

\section{Dilution Effects (spiked vs. unspiked)}

More E. coli was recovered from spiked manure samples than from unspiked manure samples and fewer colonies from manure grew with each dilution. For both systems about as much $E$. coli was recovered as was inoculated.

\section{Effect of reducing competitive organisms (sterile Vs raw)}

Except for the first dilution, there was no difference detected in E. coli recovery between sterile and raw manure. On average, 21.4 more E. coli colonies (51.88 colonies) were recovered from sterile manure spiked with the target organism at the highest concentration level than from raw manure (30.48 colonies) spiked at the highest concentration.

\section{Media Effects (CHROMagar vs. CT Smac)}

Only once was a difference detected in E. coli colonies from manure between CHROMagar and CT Smac media. E. coli growth on CHROMagar plates was slightly greater for Spike 1 water samples than on CT Smac plates (mean difference 0.58). When unspiked raw manure was incubated for 18-24 h before plating, CT Smac plates had slightly more E. coli colonies than CHROMagar plates (mean difference 0.61). No difference between numbers of colonies was detected between the two media for sterile manure or when the data was combined for sterile and raw manure.

\section{Incubation Effects (incubated vs. non-incubated)}

No differences in E. coli colony counts were detected between incubated and non-incubated non-spiked manure. 


\section{Technician Effects (M vs. D)}

No differences in E. coli recovery were detected between technicians.

\section{Run Effects (A1-A7 and M1-M7)}

No differences in E. coli recovery was detected between runs, racks, or position of sample in the rack, or size of run.

\section{Source of sample (pat identification)}

No differences were detected in E. coli counts between "pats".

\section{Sample Material (Manure vs. Water)}

No differences were detected between manure and water for any Mode or dilution.

\section{Growth of Target Organisms in Sterile Water}

For either system, sterile water should not include the target organism. However, all sterile water samples for the first manual run performed and sterile water samples in one of the automated runs were contaminated with target organisms. Since, different technicians did these two runs, the likelihood that both technicians would contaminate sterile was low. We learned that the technician who prepared the sterile water samples had trouble with the pipette that was used, discarded it and began using another pipette to prepare the remaining sterile water samples. The malfunctioning pipette was the most likely explanation for the contaminated sterile water. No plates of the source of the sterile water were made which would have provided definitive proof that the water samples had been contaminated. The laboratory has since modified its standard operation procedures so that plates of all batches of prepared reagents and media are incubated and examined for microbiological growth before and after use in experiments. The observations from the contaminated runs were omitted from the analysis and the contaminated runs were redone. After determining that no contamination had occurred during the repeated runs, they were included in the analysis.

One suspect target organism colony was found in a sterile water sample that could not be explained by contamination. That bacterial colony was further tested and determined not to be the target organism. Therefore, all sterile water samples were free of contamination indicating that neither system (A or M) lead to contamination of adjacent samples of sterile water.

\section{Growth of Non-Target Organisms (background) in Non-Spiked Sterile Water}

Under the null hypothesis, non-targeted bacteria (background) should be absent unless a treatment effect occurred. The analysis detected a significant difference in background growth from non-spiked sterile water samples between systems and media. On further analysis a pattern became 
evident: All sterile water samples processed by the automated system and plated on CA had background growth except the first run and the last run, which was the repeated run.

\section{Growth of Non-Target Organisms (background) in Non-Spiked Sterile Manure}

Under the null hypothesis, non-targeted background bacteria should be absent from sterile manure samples unless a treatment effect occurred. The analysis detected the identical effects and pattern as was detected from the analysis of background growth in sterile water.

\section{Growth of Non-Target Organisms in Spiked Water}

Even though water samples that were spiked were expected to have bacterial growth on the media, no non-target bacterial colonies should grow under the null hypothesis, because the water was sterile before inoculation with the target organism. The analysis detected background bacterial growth in the identical pattern observed in the non-spiked sterile samples.

These observations lead to the discovery that the wash solution became contaminated after the first run with the automated system and contaminated all remaining runs except the final run which was done with a different batch of wash solution. Fortunately, the contaminated wash solution was used only for the automated system and not for the manual system which used a different batch of wash solution. Had only one batch been used for both systems, the contamination problem would not have been detected especially because the wash solution was not tested before or after the experiment for contamination.

\section{DISCUSSION}

The analysis confirmed what was perhaps obvious to the microbiologist: that more target organisms were recovered when the sample was artificially contaminated with higher concentrations of target organisms than from lower concentrations. Perhaps what would have not been so obvious, but for the structured design of the experiment and some precautions taken by the laboratory to make the equipment, solutions, and procedures used for each system independent of one another, was the discovery of two contamination events: 1) that the sterile water used was contaminated with the target organism for two of the runs, and 2) that the wash solution used for the automated system became contaminated after the first run. The structured design of the experiment lead to the discovery that the buffer solution had been contaminated only for the automated system (because a different batch of buffer was used for each system) and that contamination only occurred on CA media (because CT media contains antibiotics that limit background growth). Had this exploration of the dataset not been done, an incorrect inference would have been made: that the automated system somehow was increasing background growth. The structured design further allowed certain comparisons to be made that were valid.

This work shows the importance of having all materials used and activities performed during an experiment independent of one another, the importance of a structured design, and the value of side-by-side interaction between statistician and client. 


\section{REFERENCES}

Milliken, G.A. and Johnson, D.E. (1992). The Analysis of Messy Data, Vol I: Designed Experiments, London:Chapman \& Hall.

SAS Institute, Inc. (1989) SAS/STAT ${ }^{\mathrm{R}}$ User's Guide, Version 6, Fourth Edition, Volume 2, Cary, $\mathrm{NC}:$ SAS Institute Inc. 
Table 1. Treatment combinations for experiments 1 and 2 that used the same fecal pat's (patties).

\begin{tabular}{|c|c|c|c|c|c|c|c|c|c|c|c|c|c|c|c|}
\hline & & \multicolumn{9}{|c|}{ Experiment 1} & \multicolumn{5}{|c|}{ Experiment 2} \\
\hline \multirow{2}{*}{\multicolumn{2}{|c|}{$\begin{array}{ll}\text { m } & \text { Syste } \\
& \text { Tech } \\
\end{array}$}} & \multicolumn{6}{|c|}{ Automated } & \multicolumn{3}{|c|}{ Manual } & \multicolumn{3}{|c|}{ Automated } & \multicolumn{2}{|c|}{ Manual } \\
\hline & & \multicolumn{2}{|c|}{$\mathrm{M}$} & \multicolumn{2}{|c|}{$\mathrm{D}$} & \multicolumn{2}{|c|}{$\mathrm{M}$} & $\mathrm{D}$ & $\mathrm{M}$ & $\mathrm{D}$ & \multicolumn{2}{|c|}{$\mathrm{D}$} & M & $\mathrm{M}$ & $\mathrm{D}$ \\
\hline \multicolumn{2}{|r|}{ Cycle } & \multicolumn{2}{|c|}{1} & \multicolumn{2}{|c|}{2} & \multicolumn{2}{|c|}{3} & 6 & 7 & 8 & \multicolumn{2}{|c|}{4} & 5 & 9 & 10 \\
\hline Pat & Run & 1 & 2 & 1 & 2 & 1 & 2 & 1 & 1 & 1 & 1 & 2 & 1 & 1 & 1 \\
\hline \multirow[t]{2}{*}{1} & Sterile & $\mathrm{Sl}$ & & & & & & $\mathrm{Sl}$ & & & $\begin{array}{l}\text { S0 } \\
\text { S2 } \\
\text { S3 } \\
\end{array}$ & & & $\begin{array}{l}\text { S0 } \\
\text { S2 } \\
\text { S3 } \\
\end{array}$ & \\
\hline & Raw & $\mathrm{S} 1$ & & & & & & $\mathrm{~S} 1$ & & & $\begin{array}{l}\text { S0 } \\
\text { S2 } \\
\text { S3 } \\
\end{array}$ & & & $\begin{array}{l}\text { S0 } \\
\text { S2 } \\
\text { S3 } \\
\end{array}$ & \\
\hline \multirow[t]{2}{*}{2} & Sterile & $\mathrm{S} 1$ & & & & & & $\mathrm{~S} 1$ & & & $\begin{array}{l}\text { S0 } \\
\text { S2 } \\
\text { S3 } \\
\end{array}$ & & & $\begin{array}{l}\text { S0 } \\
\text { S2 } \\
\text { S3 } \\
\end{array}$ & \\
\hline & Raw & $\mathrm{S} 1$ & & & & & & S1 & & & $\begin{array}{l}\text { S2 } \\
\text { S3 }\end{array}$ & S0 & & $\begin{array}{l}\text { S0 } \\
\text { S2 } \\
\text { S3 } \\
\end{array}$ & \\
\hline \multirow[t]{2}{*}{3} & Sterile & $\mathrm{S} 1$ & & & & & & S1 & & & & $\begin{array}{l}\text { S0 } \\
\text { S2 } \\
\text { S3 } \\
\end{array}$ & & & $\begin{array}{l}\text { S0 } \\
\text { S2 } \\
\text { S3 } \\
\end{array}$ \\
\hline & Raw & $\mathrm{S} 1$ & & & & & & S1 & & - & & $\begin{array}{l}\text { S0 } \\
\text { S2 } \\
\text { S3 } \\
\end{array}$ & & & $\begin{array}{l}\text { S0 } \\
\text { S2 } \\
\text { S3 } \\
\end{array}$ \\
\hline \multirow[t]{2}{*}{4} & Sterile & & $\mathrm{S} 1$ & & & & & S1 & & & & $\begin{array}{l}\text { S2 } \\
\text { S3 }\end{array}$ & S0 & & $\begin{array}{l}\text { S0 } \\
\text { S2 } \\
\text { S3 }\end{array}$ \\
\hline & Raw & & $\mathrm{S} 1$ & & & & & S1 & & & & $\begin{array}{l}\text { S2 } \\
\text { S3 }\end{array}$ & S0 & & $\begin{array}{l}\text { S0 } \\
\text { S2 } \\
\text { S3 } \\
\end{array}$ \\
\hline \multirow[t]{2}{*}{5} & Sterile & & $\mathrm{S1}$ & & & & & $\mathrm{S} 1$ & & & & & $\begin{array}{l}\text { S0 } \\
\text { S2 } \\
\text { S3 } \\
\end{array}$ & $\begin{array}{l}\text { S2 } \\
\text { S3 }\end{array}$ & So \\
\hline & Raw & & $\mathrm{S} 1$ & & & & & S1 & & & & & $\begin{array}{l}\text { S0 } \\
\text { S2 } \\
\text { S3 } \\
\end{array}$ & $\begin{array}{l}\text { S2 } \\
\text { S3 }\end{array}$ & so \\
\hline Water & Sterile & $\begin{array}{l}7 \mathrm{~S} 0 \\
2 \mathrm{~S} 1 \\
\end{array}$ & $\begin{array}{l}8 \mathrm{~S} 0 \\
3 \mathrm{~S} 1 \\
\end{array}$ & $\begin{array}{l}7 \mathrm{~S} 0 \\
3 \mathrm{~S} 1 \\
\end{array}$ & $\begin{array}{l}8 \mathrm{~S} 0 \\
2 \mathrm{~S} 1 \\
\end{array}$ & $\begin{array}{l}7 \mathrm{~S} 0 \\
3 \mathrm{~S} 1 \\
\end{array}$ & $\begin{array}{l}2 \mathrm{~S} 0 \\
2 \mathrm{~S} 1 \\
\end{array}$ & $\begin{array}{c}15 \mathrm{~S} 0 \\
5 \mathrm{~S} 1 \\
\end{array}$ & $\begin{array}{c}15 \mathrm{~S} 0 \\
5 \mathrm{~S} 1 \\
\end{array}$ & $\begin{array}{c}15 \mathrm{~S} 0 \\
5 \mathrm{~S} 1 \\
\end{array}$ & $\begin{array}{l}2 \mathrm{~S} 2 \\
2 \mathrm{~S} 3 \\
\end{array}$ & $\begin{array}{l}2 \mathrm{~S} 2 \\
2 \mathrm{~S} 3 \\
\end{array}$ & $\begin{array}{l}\mathrm{S} 2 \\
\mathrm{~S} 3 \\
\end{array}$ & $\begin{array}{l}2 \mathrm{~S} 2 \\
2 \mathrm{~S} 3 \\
\end{array}$ & $\begin{array}{l}3 \mathrm{~S} 2 \\
3 \mathrm{~S} 3 \\
\end{array}$ \\
\hline Wate & Batch & 106 & 107 & 201 & 202 & 306 & 307 & 601 & 706 & 801 & 401 & 402 & 506 & 906 & 1001 \\
\hline
\end{tabular}


Table 1 (continued). Treatment combinations run on additional pats for experiment 1.

\begin{tabular}{|c|c|c|c|c|c|c|c|c|c|c|}
\hline & \multicolumn{10}{|c|}{ Experiment 1} \\
\hline & System & \multicolumn{6}{|c|}{ Automated } & \multicolumn{3}{|c|}{ Manual } \\
\hline & Tech & \multicolumn{2}{|c|}{$\mathrm{M}$} & \multicolumn{2}{|c|}{$\mathrm{D}$} & \multicolumn{2}{|c|}{$\mathrm{M}$} & $\mathrm{D}$ & $\mathrm{M}$ & $\mathrm{D}$ \\
\hline & Cycle & \multicolumn{2}{|c|}{1} & \multicolumn{2}{|c|}{2} & \multicolumn{2}{|c|}{3} & 6 & 7 & 8 \\
\hline Patty & Run & 1 & 2 & 1 & 2 & 1 & 2 & 1 & 1 & 1 \\
\hline \multirow{2}{*}{6} & Sterile & & & S1 & & & & & $\mathrm{S} 1$ & \\
\hline & Raw & & & $\mathrm{S} 1$ & & & & & $\mathrm{~S} 1$ & \\
\hline \multirow{2}{*}{7} & Sterile & & & $\mathrm{S} 1$ & & & & & $\mathrm{~S} 1$ & \\
\hline & Raw & & & $\mathrm{S} 1$ & & & & & $\mathrm{~S} 1$ & \\
\hline \multirow{2}{*}{8} & Sterile & & & & S1 & & & & $\mathrm{S} 1$ & \\
\hline & Raw & & & $\mathrm{S} 1$ & & & & & $\mathrm{~S} 1$ & \\
\hline \multirow{2}{*}{9} & Sterile & & & & $\mathrm{S} 1$ & & & & $\mathrm{~S} 1$ & \\
\hline & Raw & & & & S1 & & & & $\mathrm{S} 1$ & \\
\hline \multirow[b]{2}{*}{10} & Sterile & & & & S1 & & & & $\mathrm{S} 1$ & \\
\hline & Raw & & & & S1 & & & & $\mathrm{S} 1$ & \\
\hline \multirow[b]{2}{*}{11} & Sterile & & & & & $\mathrm{S} 1$ & & & & $\mathrm{~S} 1$ \\
\hline & Raw & & & & & $\mathrm{Sl}$ & & & & $\mathrm{S} 1$ \\
\hline \multirow{2}{*}{12} & Sterile & & & & & $\mathrm{S} 1$ & & & & $\mathrm{~S} 1$ \\
\hline & Raw & & & & & $\mathrm{S} 1$ & & & & $\mathrm{~S} 1$ \\
\hline \multirow{2}{*}{13} & Sterile & & & & & $\mathrm{S} 1$ & & & & $\mathrm{~S} 1$ \\
\hline & Raw & & & & & & $\mathrm{Sl}$ & & & $\mathrm{S} 1$ \\
\hline \multirow{2}{*}{14} & Sterile & & & & & & $\mathrm{S} 1$ & & & $\mathrm{~S} 1$ \\
\hline & Raw & & & & & & $\mathrm{Sl}$ & & & $\mathrm{S} 1$ \\
\hline \multirow[b]{2}{*}{15} & Sterile & & & & & & S1 & & & $\mathrm{S} 1$ \\
\hline & Raw & & & & & & $\mathrm{S} 1$ & & & $\mathrm{~S} 1$ \\
\hline
\end{tabular}


Table 2. Experiment 1, automated system.

Technician M, Cycle 1

Run 1

Rack

\begin{tabular}{|l|}
\hline \multicolumn{1}{c|}{1} \\
SMS1 \\
\hline S1
\end{tabular}

\begin{tabular}{|c|}
\hline SWS0 \\
\hline $\begin{array}{l}\text { SMS1 } \\
\text { P2 }\end{array}$ \\
\hline SWS0 \\
\hline $\begin{array}{l}\text { RMS1 } \\
\text { P2 }\end{array}$ \\
\hline SWS0 \\
\hline
\end{tabular}

Run 1

Rack

\begin{tabular}{|l|}
\hline \multicolumn{1}{c}{1} \\
RMS1 \\
\hline SWS0 \\
\hline SWS1 \\
\hline SWS0 \\
\hline $\begin{array}{l}\text { SMS1P } \\
6\end{array}$ \\
\hline
\end{tabular}

\begin{tabular}{|l|}
\hline \multicolumn{1}{c|}{2} \\
\hline SWS0 \\
\hline $\begin{array}{l}\text { RMS1 } \\
\text { P7 }\end{array}$ \\
\hline SWS0 \\
\hline SWS1 \\
\hline SWS0 \\
\hline
\end{tabular}

Run 1

Rack

\begin{tabular}{|l|}
\multicolumn{1}{c|}{1} \\
\hline SWS1 \\
\hline SWS0 \\
\hline $\begin{array}{l}\text { SMS1 } \\
\text { P11 }\end{array}$ \\
\hline SWS0 \\
\hline $\begin{array}{l}\text { RMS1 } \\
\text { P11 }\end{array}$ \\
\hline
\end{tabular}

\begin{tabular}{|l|}
\hline \multicolumn{1}{c|}{2} \\
\hline SWS0 \\
\hline SWS1 \\
\hline SWS0 \\
\hline SMS1 \\
\hline P12 \\
\hline SWS0 \\
\hline
\end{tabular}

\begin{tabular}{|l|}
\hline \multicolumn{1}{c|}{3} \\
\hline SWS1 \\
\hline SWS0 \\
\hline $\begin{array}{l}\text { SMS1 } \\
\text { P3 }\end{array}$ \\
\hline SWS0 \\
\hline $\begin{array}{l}\text { RMS1 } \\
\text { P3 }\end{array}$ \\
\hline
\end{tabular}

Technician D, Cycle 2
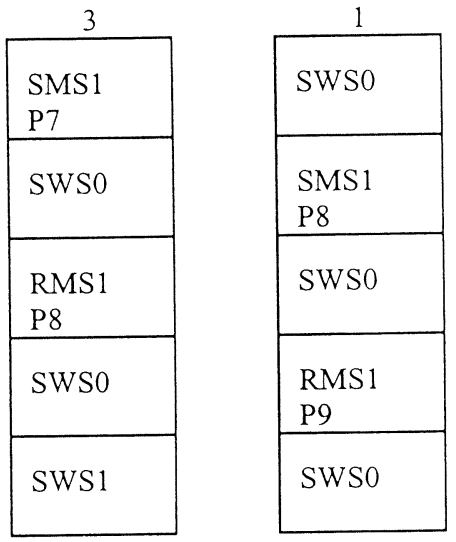

Technician M, Cycle 3

\begin{tabular}{|l|}
\hline \multicolumn{1}{c|}{1} \\
\hline SWS0 \\
\hline SWS1 \\
\hline SWS0 \\
\hline SMS1 \\
\hline 4 \\
\hline SWS0 \\
\hline
\end{tabular}

Run 2

\begin{tabular}{|c|}
\hline $\begin{array}{l}\text { RMS1 } \\
\mathrm{P} 4\end{array}$ \\
\hline SWS0 \\
\hline SWS1 \\
\hline SWS0 \\
\hline $\begin{array}{l}\text { SMS1 } \\
\text { P5 }\end{array}$ \\
\hline
\end{tabular}

\begin{tabular}{|l|}
\hline \multicolumn{1}{|c|}{3} \\
\hline SWS0 \\
\hline $\begin{array}{l}\text { RMS0 } \\
\text { P5 }\end{array}$ \\
\hline SWS0 \\
\hline SWS0 \\
\hline SWS0 \\
\hline
\end{tabular}

Run 2

\begin{tabular}{|l|}
\hline \multicolumn{1}{c|}{2} \\
\hline SWS1 \\
\hline SWS0 \\
\hline $\begin{array}{l}\text { SMS1 } \\
\text { P9 }\end{array}$ \\
\hline SWS0 \\
\hline $\begin{array}{l}\text { RMS1 } \\
\text { P10 }\end{array}$ \\
\hline
\end{tabular}

\begin{tabular}{|l|}
\hline \multicolumn{1}{c}{3} \\
\hline SWS0 \\
\hline SWS1 \\
\hline SWS0 \\
\hline $\begin{array}{l}\text { SMS1 } \\
\text { P10 }\end{array}$ \\
\hline SWS0 \\
\hline
\end{tabular}

Run 2

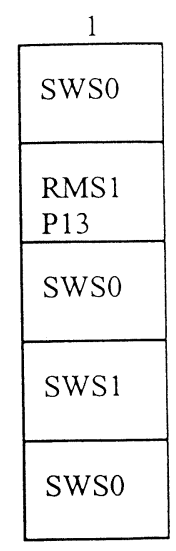

\begin{tabular}{|l|}
\hline \multicolumn{1}{c|}{3} \\
\hline SWS0 \\
\hline $\begin{array}{l}\text { SSM } \\
\text { P15 }\end{array}$ \\
\hline SWS0 \\
\hline SRM \\
P15 \\
\hline SWS0 \\
\hline
\end{tabular}


Table 3. Experiment 1, Manual System

\begin{tabular}{|c|c|c|c|c|c|c|c|c|c|c|}
\hline \multicolumn{11}{|c|}{ Technician D, Cycle 1} \\
\hline $\begin{array}{l}\text { Rack } \\
1\end{array}$ & $\begin{array}{l}\text { SMS1 } \\
\text { P1 }\end{array}$ & SWS0 & $\begin{array}{l}\text { RMS1 } \\
\text { P1 }\end{array}$ & SWS0 & SWS1 & SWS0 & $\begin{array}{l}\text { SMS1 } \\
\mathrm{P} 2\end{array}$ & SWS0 & $\begin{array}{l}\text { RMS1 } \\
\text { P2 }\end{array}$ & SWS0 \\
\hline $\begin{array}{l}\text { Rack } \\
2 \\
\end{array}$ & SWS1 & SWS0 & $\begin{array}{l}\text { SMS1 } \\
\mathrm{P} 3 \\
\end{array}$ & SWS0 & $\begin{array}{l}\text { RMS1 } \\
\text { P3 } \\
\end{array}$ & SWS0 & SWS1 & SWS0 & $\begin{array}{l}\text { SMS1 } \\
\text { P4 }\end{array}$ & SWS0 \\
\hline $\begin{array}{l}\text { Rack } \\
3 \\
\end{array}$ & $\begin{array}{l}\text { RMS1 } \\
\text { P4 }\end{array}$ & SWS0 & SWS1 & SWS0 & $\begin{array}{l}\text { SMS1 } \\
\text { P5 }\end{array}$ & SWS0 & $\begin{array}{l}\text { RMS1 } \\
\text { P5 }\end{array}$ & SWSO & SWS1 & SWS0 \\
\hline \multicolumn{11}{|c|}{ Technician M, Cycle 2} \\
\hline $\begin{array}{l}\text { Rack } \\
1\end{array}$ & $\begin{array}{l}\text { RMS1 } \\
\text { P6 }\end{array}$ & & SWS1 & SWS0 & $\begin{array}{l}\text { SMS1 } \\
\text { P6 }\end{array}$ & SWS0 & $\begin{array}{l}\text { RMS1 } \\
\text { P7 }\end{array}$ & SWS0 & SWS1 & SWS0 \\
\hline $\begin{array}{l}\text { Rack } \\
2 \\
\end{array}$ & $\begin{array}{l}\text { SMS1 } \\
\text { P7 }\end{array}$ & SWS0 & $\begin{array}{l}\text { RMS1 } \\
\text { P8 }\end{array}$ & SWS0 & SWS1 & SWS0 & $\begin{array}{l}\text { SMS1 } \\
\text { P8 }\end{array}$ & SWS0 & $\begin{array}{l}\text { RMS1 } \\
\text { P9 }\end{array}$ & SWS0 \\
\hline $\begin{array}{l}\text { Rack } \\
3 \\
\end{array}$ & SWS1 & SWS0 & $\begin{array}{l}\text { SMS1 } \\
\text { P9 }\end{array}$ & SWS0 & $\begin{array}{l}\text { RMS1 } \\
\mathrm{P} 10\end{array}$ & SWS0 & SWS1 & SWS0 & $\begin{array}{l}\text { SMS1 } \\
\mathrm{P} 10\end{array}$ & SWS0 \\
\hline \multicolumn{11}{|c|}{ Technician D, Cycle 3} \\
\hline $\begin{array}{l}\text { Rack } \\
1 \\
\end{array}$ & SWS1 & SWS0 & $\begin{array}{l}\text { SMS1 } \\
\text { P11 }\end{array}$ & SWS0 & $\begin{array}{l}\text { RMS1 } \\
\text { P11 } \\
\end{array}$ & SWS0 & SWS1 & SWS0 & $\begin{array}{l}\text { SMS1 } \\
\mathrm{P} 12\end{array}$ & SWS0 \\
\hline $\begin{array}{l}\text { Rack } \\
2 \\
\end{array}$ & $\begin{array}{l}\text { RMS1 } \\
\text { P12 }\end{array}$ & SWS0 & SWS1 & SWS0 & $\begin{array}{l}\text { SMS1 } \\
\mathrm{P} 13 \\
\end{array}$ & SWS0 & $\begin{array}{l}\text { RMS1 } \\
\text { P13 }\end{array}$ & SWS0 & SWS1 & SWS0 \\
\hline $\begin{array}{l}\text { Rack } \\
3\end{array}$ & $\begin{array}{l}\text { SMS1 } \\
\text { P14 }\end{array}$ & SWS0 & $\begin{array}{l}\text { RMS1 } \\
\text { P14 }\end{array}$ & SWS0 & SWS1 & SWS0 & $\begin{array}{l}\text { SMS1 } \\
\text { P15 }\end{array}$ & SWS0 & $\begin{array}{l}\text { RMS1 } \\
\text { P15 }\end{array}$ & SWS0 \\
\hline
\end{tabular}

Table 4. Fixed and random effects used to explain the observed colonies of the target organism.

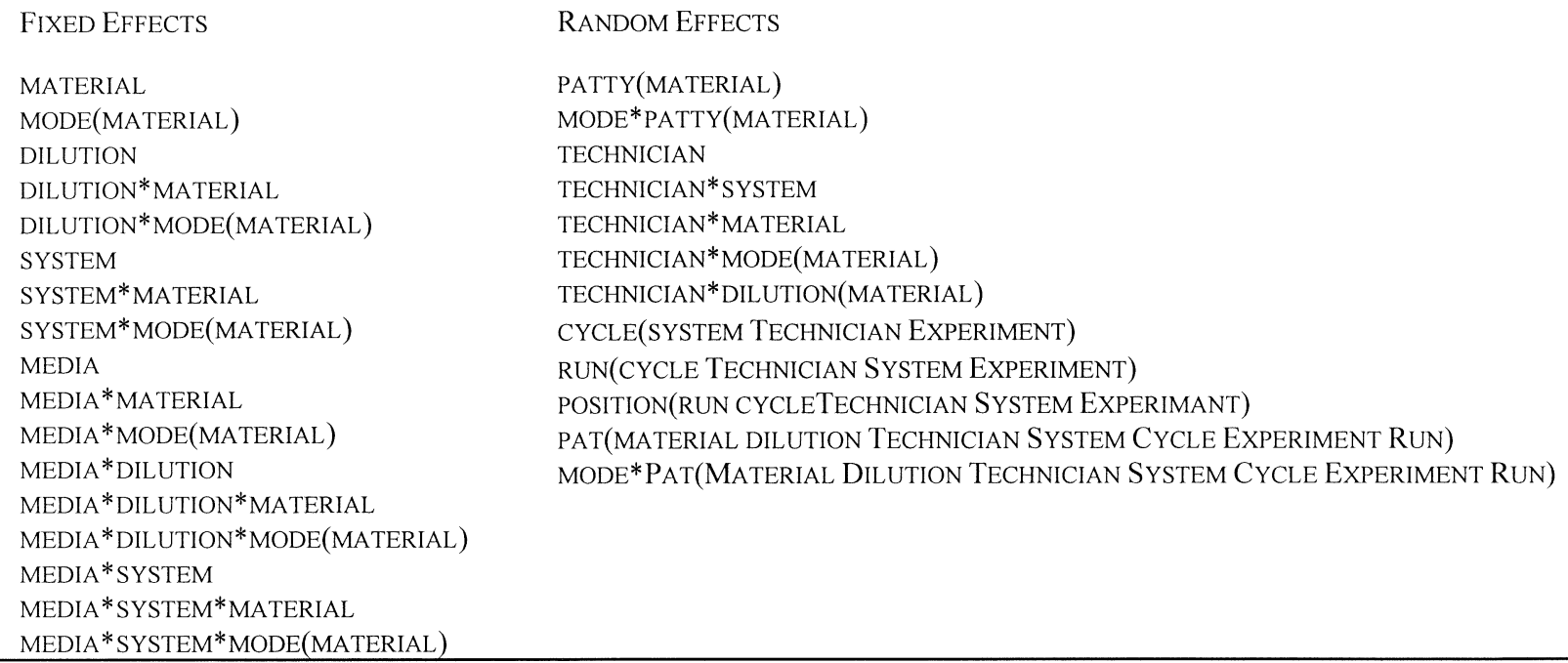


Table 5. Type 3 tests of fixed effects.

\begin{tabular}{lrrrr}
\multicolumn{1}{c}{ Effect } & Num & $\begin{array}{r}\text { Den } \\
\text { DF }\end{array}$ & F & Pr $>$ F \\
\hline SYSTEM & 1 & 8.96 & 1.78 & 0.22 \\
DILUTION*MODE*MEDIA(MATERIAL*EXPERIMENT) & 27 & 30.90 & 14.48 & $<0.00$ \\
DILUTION*MODE*SYSTEM*MEDIA(MATERIAL*EXPERIMENT) & 27 & 61.60 & 1.30 & 0.20 \\
\hline
\end{tabular}

Table 6. Some significant lsmeans comparisons with differences of log of target bacteria counts

Sterile Vs. Raw Manure Comparisons

$\begin{array}{lll}\text { Sterile Manure } & \text { > Raw Manure, Spike 1 } & 0.52 \\ \text { Sterile Manure on Agar } & \text { > Raw Manure, Spike 1 } & 0.51 \\ \text { Sterile Manure on CTS } & \text { > Raw Manure, Spike 1 } & 0.52\end{array}$

Comparisons of All Manure Spiked with Different Concentrations of E. coli

$\begin{array}{lll}\text { Spike 1 Manure } & \text { > Spike 0 Manure } & 3.59 \\ \text { Spike 2 Manure } & \text { > Spike 0 Manure } & 2.12 \\ \text { Spike 3 Manure } & \text { > Spike 0 Manure } & 0.99 \\ & & \\ \text { Spike 1 Manure } & \text { > Spike 2 Manure } & 1.46 \\ \text { Spike 1 Manure } & \text { > Spike 3 Manure } & 2.60 \\ \text { Spike 2 Manure } & \text { > Spike 3 Manure } & 1.14\end{array}$

Comparisons of Raw Manure Spiked with Different Concentrations of E. coli and Raw Manure Not Spiked

Spike 1 Raw Manure $>$ Spike 0 Raw Manure

Spike 2 Raw Manure > Spike 0 Raw Manure $\quad 2.06$

Spike 3 Raw Manure > Spike 0 Raw Manure $\quad 0.74$

Comparisons of Sterile Manure Spiked with Different Concentrations of E. coli and Sterile Manure Not Spiked

Spike 1 Sterile Manure > Spike 0 Sterile Manure 
Figure 1. Treatment structure of experiments. Fecal pats were divided into two portions (sterile and raw) and each portion was divided into 4 subportions. Subportions were not inoculated with the target species (S0) or inoculated with 1 of 3 concentrations of the target species (S1, S2, or S3 where S1 was the highest concentration). Sterile water was inoculated with 3 concentrations of the target organism or not inoculated (control). These 12 were distributed over two experiments (E1 and E2). The 12 treatments shown here were run for each system (automated and manual) for a total of 24 treatments.

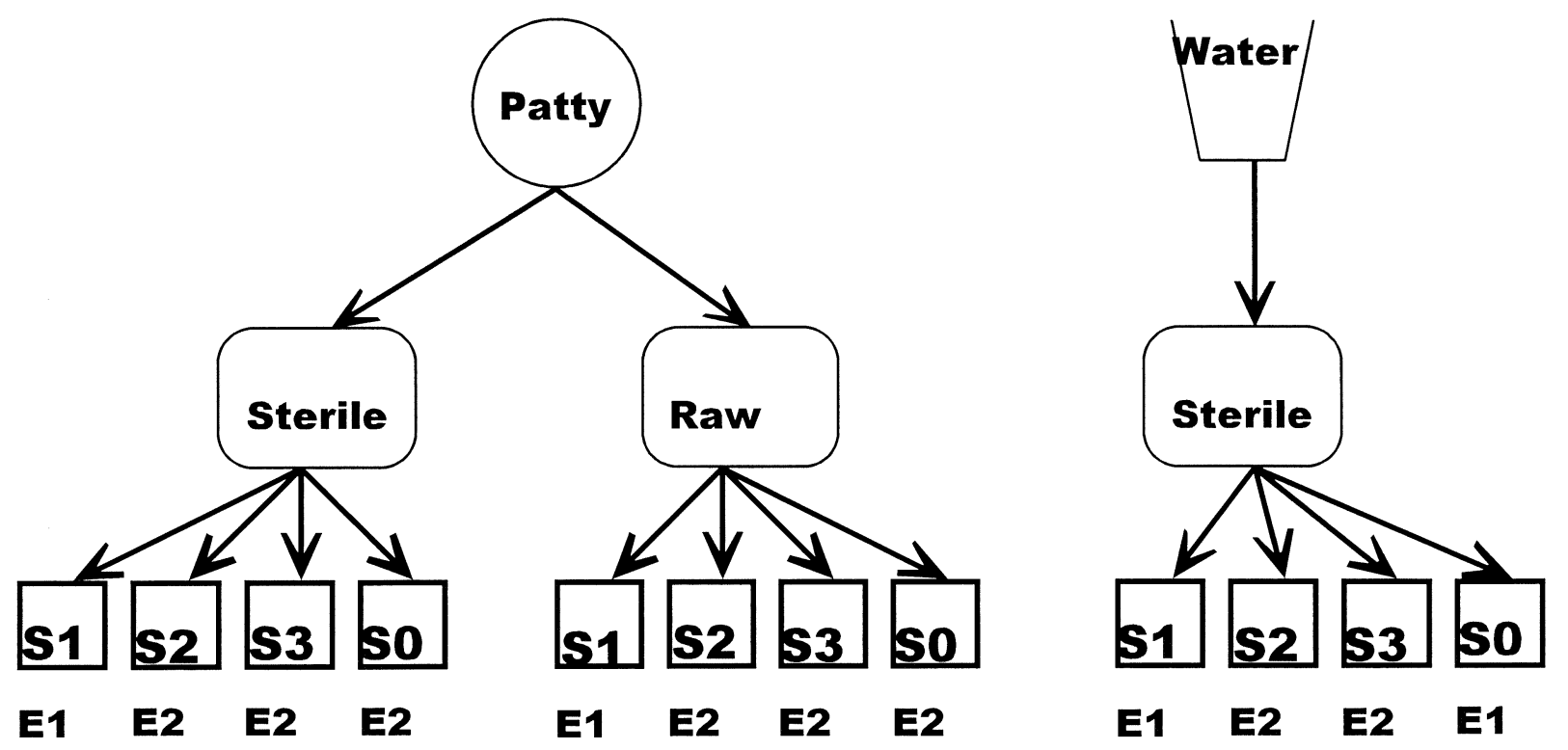

Figure 2. Each Treatment (e.g., S1) was placed onto 2 types of bacterial growth media plates: ChromAGAR (CA) and CT Smac (CT). The response variable was the number of target bacteria colonies growing on each plate.

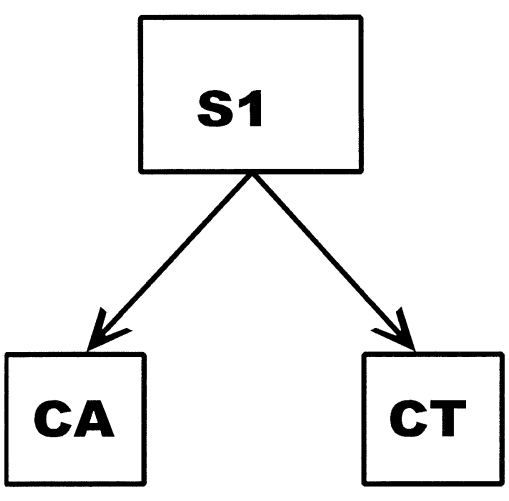

